\title{
Studying the Performance of Cognitive Models in Time Series Forecasting
}

\author{
Estudando o Desempenho de Modelos Cognitivos para Previsão de Séries Temporais
}

\author{
Ademir Batista dos Santos Neto ${ }^{1}$, Maria da Conceição Moraes Batista ${ }^{1}$, Paulo Renato Alves

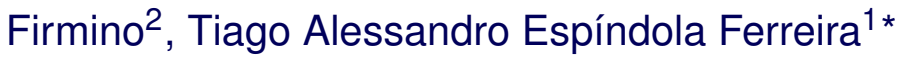

\begin{abstract}
Cognitive models have been paramount for modeling phenomena for which empirical data are unavailable, scarce, or only partially relevant. These approaches are based on methods dedicated to preparing experts and then to elicit their opinions about the variables that describe the phenomena under study. In time series forecasting exercises, elicitation processes seek to obtain accurate estimates, overcoming human heuristic biases, while being less time consuming. This paper aims to compare the performance of cognitive and mathematical time series predictors, regarding accuracy. The results are based on the comparison of predictors of the cognitive and mathematical models for several time series from the M3-Competition. From the results, one can see that cognitive models are, at least, as accurate as ARIMA models predictions.
\end{abstract}

Keywords: Cognitive Models - ARIMA Models - Elicitation of Knowledge - Time Series Forecasting

Resumo: Modelos cognitivos têm sido usados na modelagem de fenômenos onde dados empíricos são indisponíveis, escassos ou apenas parcialmente relevantes. Essa abordagem é baseada em métodos dedicados a preparar especialistas e eduzir suas opiniões a respeito de variáveis de interesse que podem descrever o fenômeno em questão. Na previsão de séries temporais, a edução do conhecimento tem como objetivo obter estimações acuradas, superando os vieses humanos intrínsecos, enquanto que deixa o processo mais eficiente. Esse artigo trata de uma comparação do desempenho em termos de acurácia de modelos cognitivos e matemáticos na previsão de algumas séries temporais da M3-Competition. A partir dos resultados é possível avaliar que modelos cognitivos são ao menos tão acurados quanto os modelos ARIMA para as predições avaliadas.

Palavras-Chave: Modelos Cognitivos - Modelos ARIMA - Elicitação do Conhecimento - Previsão de Séries Temporais

${ }^{1}$ DEInfo - Statistic and Informatic Departament, Federal Rural University of Pernambuco, Brazil

${ }^{2}$ Center for Science and Technology, Federal University of Cariri, Brazil

*Corresponding author: taef.first@gmail.com

DOI: http://dx.doi.org/10.22456/2175-2745.96181 • Received: 03/09/2019 • Accepted: 25/11/2019

CC BY-NC-ND 4.0 - This work is licensed under a Creative Commons Attribution-NonCommercial-NoDerivatives 4.0 International License.

\section{Introduction}

Opinions are sometimes imperative for the adequate modeling and forecasting of stochastic phenomena. Forecasters thus resort to cognitive models, i.e. an approximation of the animal cognitive process (predominantly human) aimed to comprehend and predict dynamic systems [1]. These models can be developed with or without a cognitive architecture. Although these classes of models are not always easily distinguishable [2], the resulting forecaster's opinions are the synthesis of its cognitive components.
On the other hand, mathematical models fail in incorporating disturbances not observed during the modeling phase, also justifying the importance of cognitive models. Further, must mathematical models need a large number of empirical data to adequately describe the phenomena. In fact, the scarcity of data has presented itself as one of the main challenges to the models based on empirical data [3]. In areas like probabilistic risk analysis, where the scarcity of data comes from the attempt of modeling rare events, it has been challenging [4]. According to MacCormack et al. [5], due to the usual behavior of dynamic systems, historical data can not be the 
only source to supply the requirements of the probabilistic risk analysis, also demanding experts' opinions. Therefore, cognitive models have been valuable [6].

An expert can be defined as someone who has a particular knowledge about a specific topic [7]. Mainly, someone can be considered an expert when this person has a recognized knowledge about some topic by others researchers from this field [8]. In turn, an expert opinion can be defined as a formal judgment over some topic for which knowledge is required. An expert opinion can also be a judgment or belief based on uncertainty. Generally, an opinion is a subjective evaluation, impression or estimate of the quantity or quality of a specific variable [7] or the association between variables. For the correct use of experts' opinions regarding variables and associations, it has been suggested the use of elicitation processes $[9,10,11]$.

Elicitation process is a set of steps which look for eliciting the knowledge $[12,13,14]$. The primary purpose of this structured and systematic approach of elicitation is to interact with the experts in a way that they can faithfully transmit their uncertainty about the characteristics of interest [15].

In time series forecasting context, it has been usual to neglect cognitive models, i.e. forecasters, and thus to fully resort to mathematical models. Time series can be defined as a set of observations organized in a chronological order, where the time is usually the index of assortment, being a discrete index [16]. The main characteristic of this kind of data is the dependency between the lags [17]. There are many mathematical models proposed to time series forecasting, such as: ARIMA [17], linear regression [18], artificial neural network [19], supported vector machine [20], Intelligent Hybrid Systems [21, 22], deep belief network [23], and others.

In this sense, the main aim of this paper is to quantitatively analyze the performance of cognitive models got from elicitation process in the thematic of time series forecasting through a comparison with ARIMA models.

The rest of the paper is divided as follows. Section 2 shows a background regarding the main topics of this paper: elicitation processes, time series, and ARIMA models. Section 3 contains the methodology of this paper, addressing the series taken into account, the methodology to get the predictions from the cognitive and mathematical models. Section 4 shows the comparison criteria and the confrontation between the results of the two modeling strategies. Finally, Section 5 has the conclusion of the paper.

\section{Background}

For the better presentation of the paper, this section introduces elicitation processes, time series, and ARIMA models. These topics will be described in the next subsections.

\subsection{Elicitation processes}

In elicitation processes, each expert can freely be considered as a source of information, inherently noise, to be decoded in some quantities during statistical modeling [24]. Under this reasoning, the process is dedicated to quantify the expert's opinions, considering not only his beliefs but also the underlying noise resulting from his human heuristics and biases. To reach this goal, fields as statistics, psychology, and computer science have worked together.

Elicitation process is a set of techniques and methods dedicated to eliciting knowledge, typically by some direct interaction with the expert [15]. The main goal of the process is to represent the expert opinions via probability distributions, allowing one to precisely measure uncertainty. The elicitation process looks for, through a set of steps, helping the expert to better express his uncertainty about his knowledge regarding some variable. This process is different from data mining because it involves the construction of information. This is a creative process and it is more complex than mining information from a set of data [25]. The right choice about the steps that will compound the elicitation process have direct influence over the final results of the elicitation, once the better the model fit to the problem the better the resulting model from the experts is [26]. To elicit expert's knowledge is a complex task once the knowledge comes from sources like randomness, cognition, and abstraction. This involves knowledge about knowledge what needs meta-cognition [27].

Clemen and Reilly [12] divide the elicitation process into five steps: (i) the evaluation on the real needing of knowledge elicitation with the empirical confirmation about data scarcity, once elicitation process is an expensive process in terms of time; (ii) the selection of the experts about the problem of interest through objective criteria, e.g. tangible proofs regarding their knowledge [7]; (iii) the training of the experts to the elicitation process; (iv) the study about the variables pertinent to the problem and their relation with the process; (v) the elicitation of opinions from the selected experts; (vi) the synthesis, analysis, and report of the opinions from the elicitation process.

The training step is very import for all process because in this step the experts begin to understand the nuances underlying the elicitation process. Inside the training, there are two main components to evaluate and correct the experts' estimations: the calibration function and the scoring rules. In the context of elicitation, calibration can be defined as a model which adjusts the experts' opinions in relationship to the biases that they can present [7]. A mathematical approach of calibration is based on constructing the model in which the expert's answers are processed and then it can be analyzed the pattern of calibration the experts are using to formulate their judgments. In this sense, the analyst can intervene in the expert in order to soften the possible effects from the biases. Cooke [9] says that mathematical models of calibration give support to the analyst against inadequate heuristics used by the experts.

In mathematical terms, the calibration model is used to find the relation between the emitted probability (given by the expert) and its expected probability (estimated by the frequency of the occurrence) about a determined event. These 
probabilities are represented by the acronyms EMP and EXP, respectively. For Any EMP in the interval $[0,1]$, the expert is calibrated when $E M P=E X P$. It means that for some determined set of events which the expert attributed a probability $E M P$, it is expected that the relative frequency of the occurrence associated to EMP get closer to EXP as the sample size grows. Figure 1 illustrates some possible calibration patterns that experts may show.

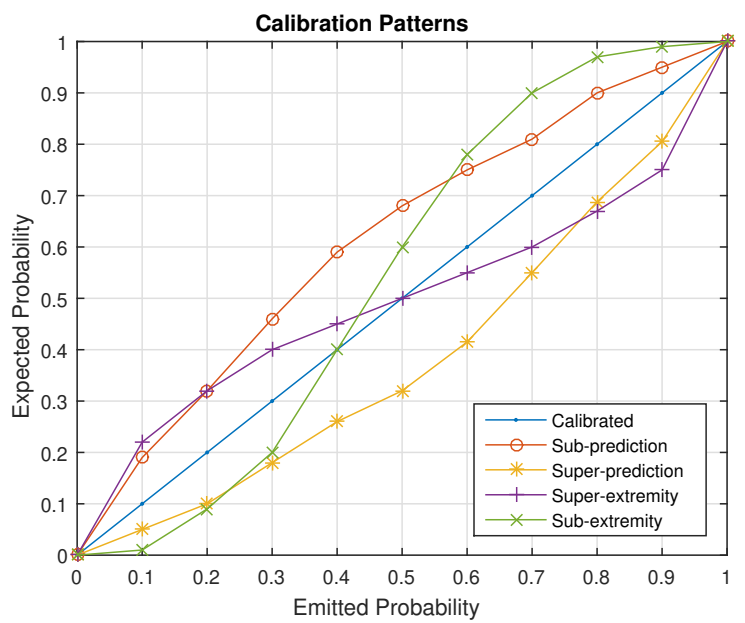

Figure 1. Possible patterns of (mis)calibration presented by experts

Following the possible (mis)calibration patterns in the Figure 1, the sub-prediction curve indicates that the expert is weakly self-confident in his opinions. This pattern indicates that the probabilities given by the expert are lesser than the relative frequency of the analyzed event, showing that the expert should be more self-confident in his judgments. The superprediction pattern indicates that the expert is being excessively self-confident. The attributed probabilities by the expert are higher than the real probabilities attributes to the events. This indicates that the expert should consider better his judgments. Sub-extremity is the pattern which the expert presents higher self-confidence when emitting probabilities under $40 \%$ (in this case) and low self-confidence when inferring about problems with probabilities higher than $40 \%$. Super-extremity occurs when the expert has weak self-confidence when attribute probabilities lowers than $50 \%$ and strongly self-confident when emitting probabilities higher than $50 \%$. All these patterns should be avoided because the expert is not being faithful to his real beliefs. The ideal pattern happens when $E M P=$ $E X P$, where the expert attributes a probability consistent to his beliefs and adjust the probabilities on the occurrence of the event, indicating that the expert is calibrated.

The scoring rules are the mathematical formalism used to evaluate forecasters. The basic idea is to attribute a note to the expert from the comparison of the probability distribution which expresses his uncertainty and the correct answers of the question [9]. One of the most known scoring rules is the quadratic score $(Q)$ introduced by Brier [28]. In this scoring rule, the experts are more rewarded as they can get more close to the real distribution of the variable. It means that the experts' opinion should be more similar possible with the relative frequency of each event. In another hand, if the expert is uncertain about some variable and far from the real distribution, the will be penalized in the evaluation. The Equation 1 presents the quadratic score formula. The vector $p=\left(p_{1}, p_{2}, \ldots, p_{n}\right)$ is the probability distribution of the variable attributed by the expert. The correct answer is represented by the canonical vector $d$, where $d_{i} \in d$ assumes the value 1, indicating $i$ as the position of the right answer in $d$, and the other values of $d, d_{j \neq i}$, are equal to zero. The lower the $Q$ value the more calibrated the expert is.

$$
Q(p)=\sum_{i=1}^{n}\left(p_{i}-d_{i}\right)^{2}
$$

\subsection{Time series prediction models}

A time series is any set of observations about some phenomena organized for some time index of ordering. The main characteristic that differentiates a time series from a regular set of data is the usual chronological dependency that the data has among them. This characteristic allows elaborate models which can be possible to forecast, e.g. which would be the next value assumed by a specified time series [29]. A fundamental characteristic in the time series analysis is stationarity. It is an elementary attribute regarding the complexity of the process, influencing directly in the modeling of the time series. A process is stationary when the mean and variance do not vary on the time. Therefore, being $y_{t}$ a point in the time series, $\mu$ its mean, $\sigma^{2}$ its variance and $\gamma$ its co-variance; the time series will be stationary if: $E\left[y_{t}\right]=\mu_{t}=\mu$; (constant mean for any time $t)$, its variance is constant represented by: $E\left[\left(y_{t}-\mu\right)^{2}\right]=E\left[\left(y_{t+s}-\mu\right)^{2}\right]=\sigma_{y}^{2}$, being $s$ a constant, and the co-variance depends only on $s$ and is described by: $E\left[y_{t}, y_{t+s}\right]=\left[\left(y_{t}-\mu\right)\left(y_{t+s}-\mu\right)\right]=\gamma_{(|s|)}[16]$. For time series that present tendencies or seasonality, there is no stationarity because this tendencies and seasonality will affect the value of the time series mean in different windows [30].

The auto-regressive integrated moving average (ARIMA) is the statistical linear model to forecast times series formalized by Box and Jenkins [17]. This is one of the most commented models in the literature about time series forecasting. The ARIMA model is a combination of two models, the autoregressive $(A R(p))$ and the moving average $(M A(q))$, with an integration of $d$ order. The architecture of the model is represented by $\operatorname{ARIMA}(p, d, q)$, in which:

- $p$ is the number of auto-regressive terms (auto-regressive order);

- $d$ is the number of differentiations need to establish stationary (integration order);

- $q$ is the number of moving average terms (moving average order). 
The autoregressive model (AR) to the interest variable is based on a linear combination of past values of the time series. Therefore the autoregressive model of order $p$ can be defined by the Equation 2:

$$
y_{t}=\phi_{1} y_{t-1}+\phi_{2} y_{t-2}+\ldots+\phi_{p} y_{t-p}+\varepsilon_{t}
$$

in which $\varepsilon_{t}$ represent a white noise term, $\phi_{i}(i=1,2, \ldots, p)$ are the autoregressive parameters, and $y_{t}$ is the time series (at time $t)$.

The moving average (MA) model instead to use past values of the series to generate a regression, uses the error of the previous predictions (or aleatory shock). The moving average model of order $q$ can be defined by the Equation 3:

$$
y_{t}=\theta_{1} \varepsilon_{t-1}+\theta_{2} \varepsilon_{t-2}+\ldots+\theta_{q} \varepsilon_{t-q}+\varepsilon_{t}
$$

in which $\theta_{i}(i=1,2, \ldots, q)$ are the parameters of the moving average model. Some series are non stationary, but present homogeneity behavior in their non stationarity. Because of this behavior it is necessary employ a number $d$ of differentiations. Assuming $d=1$, this differentiation is represented by the Equation 4:

$$
\nabla y_{t}=y_{t}-y_{t-1}
$$

in which $\nabla y_{t}$ is the derivation of the series, in a first approximation. Thus, $\nabla\left(\nabla y_{t}\right)=\nabla^{2} y_{t}$ is the second derivation and $\nabla^{d} y_{t}$ is the $d^{\text {th }}$ derivation.

A very important function to estimate the parameters to the ARIMA models is the autocorrelation function. The autocorrelation function uses the auto co-variance coefficients to generate a function that revels a correlation between any two values distant from each other by $\tau$ [17]. This function is defined by the Equation 5:

$$
\rho_{\tau}=\frac{\gamma_{\tau}}{\gamma_{0}}=\frac{E\left[\left(y_{t}-\mu\right)\left(y_{t+\tau}-\mu\right)\right]}{E\left[\left(y_{t}-\mu\right)^{2}\right]}
$$

Other function used to estimate the forecast models is the partial autocorrelation function. The partial autocorrelation function, between any two points of the series, is the correlation that remains if the impact of all the other points of the series be eliminated. Being $\phi_{k j}$ the $j^{\text {th }}$ coefficient in an autoregressive function of order $k$ [17]. In this way it is possible write the Yuli-Walker equations [17] based on the Equation 6:

$$
\rho_{j}=\phi_{k 1} \rho_{j-1}+\ldots+\phi_{k(k-1)} \rho_{j-k+1}+\phi_{k k} \rho_{j-k}
$$

with $j=1,2,3, \ldots, k$. The partial autocorrelation function is defined as the last element of the parameter $\phi$ of order $k$, or $\phi_{k k}$.

\section{Methodology}

The methodology of this paper is a comparative study with a quantitative profile to evaluate the accuracy of cognitive models applied in time series forecasting for mathematical models. In the next subsections will be addressed the series used in this paper, how was gotten the estimation for the cognitive models and the mathematical models.

\subsection{Time series cases}

The series used in this paper came from the M3-Competition [31]. The M3-Competition is a competition for time series forecasting models. The M3-Competition gives a set of times series, saying only the points, chronological order, category and the correct values for the predictions. Thereby, many models are proposed to forecast time series and the M3Competition statically analyzed them. For this comparison, 8 series were randomly selected ${ }^{1}$. These series are described in the Table 1.

\subsection{Cognitive models prediction}

To elicit opinions from experts is usually a tough task [32]. Convert expert's opinions with biases through techniques of elicitation into data which will be used in the problem modeling is not easy. The use of software aims to make the process more accessible to the expert. Software promotes more interactivity, simplicity, and the possibility to evaluate the expert's behavior during the process [33]. The tool named Mesor Elicitor $^{2}$ is a package which contains some of the main phases of the elicitation of knowledge according to Clemen and Reilly [12]. This tool implements both of the main steps, training and elicitation.

The application work through a set of steps that starts with the choice of the project until the syntheses of the results. Initially, it needs to create a new project and add all the associated questions to this new project, these questions will be related to the variables of interest. After registering the project, the system asks to register the set of experts that will compound the experiment. In the registering step, it will be provided information about the project that the expert is associated, the identification code, the methods of training and elicitation that will be used in this expert. After registering the expert, the training phase starts, with a specific number of questions, presented in a similar way that will be shown to the expert in the elicitation phase. The expert will have a feedback about his performance through the scoring rules, and the software can intervene in the expert if happens some pattern of miscalibration. After the training, the expert will be asked about a set of questions in the elicitation of the variable

\footnotetext{
${ }^{1}$ The times series are available in the electronic address https://forecasters.org/resources/time-series-data/m3-competition/

${ }^{2}$ The Mesor Elicitation was developed by the researchers: Paulo Renato, Ademir Batista and Nielson Santana. It was registered by INPI under the number BR512013000. The software is under the End User License Agreement (EULA).The software and series are avaliable on: https://github.com/ademirNeto/MesorElicitation.
} 
Table 1. Information regarding the time series used in the paper.

\begin{tabular}{llllllll}
\hline & $\begin{array}{l}\text { Quant. } \\
\text { Points }\end{array}$ & $\begin{array}{l}\text { Predicted } \\
\text { Points }\end{array}$ & $\begin{array}{l}\text { Mim. } \\
\text { Value }\end{array}$ & $\begin{array}{l}\text { Mean } \\
\text { Value }\end{array}$ & $\begin{array}{l}\text { Max. } \\
\text { Value }\end{array}$ & $\begin{array}{l}\text { Chronological } \\
\text { Order }\end{array}$ & $\begin{array}{l}\text { Type } \\
\text { of Variable }\end{array}$ \\
\hline N0236 & 38 & 3 & 1674 & 3450.6 & 5303 & Annually & Industrial \\
N0290 & 17 & 4 & 3960.5 & 4321 & 5259 & Annually & Business \\
N1037 & 44 & 6 & 2958.5 & 4198 & 5250 & Quarterly & Business \\
N1268 & 45 & 4 & 3549.6 & 4473 & 5637.8 & Quarterly & Business \\
N1269 & 27 & 5 & 5039 & 5907.2 & 9439.4 & Quarterly & Finances \\
N1459 & 51 & 8 & 750 & 2911.8 & 6600 & Monthly & Market \\
N1708 & 108 & 5 & 680 & 2012 & 5060 & Monthly & Market \\
N2355 & 108 & 2 & 2053.4 & 3324.9 & 4285.6 & Monthly & Business \\
\hline
\end{tabular}

under study. Finally, the opinions of the expert will be synthesized and the tool Mesor Elicitor will show the results to the annalist. The flowchart presented in the Figure 2 shows the steps involved in the elicitation process on the Mesor Elicitor.

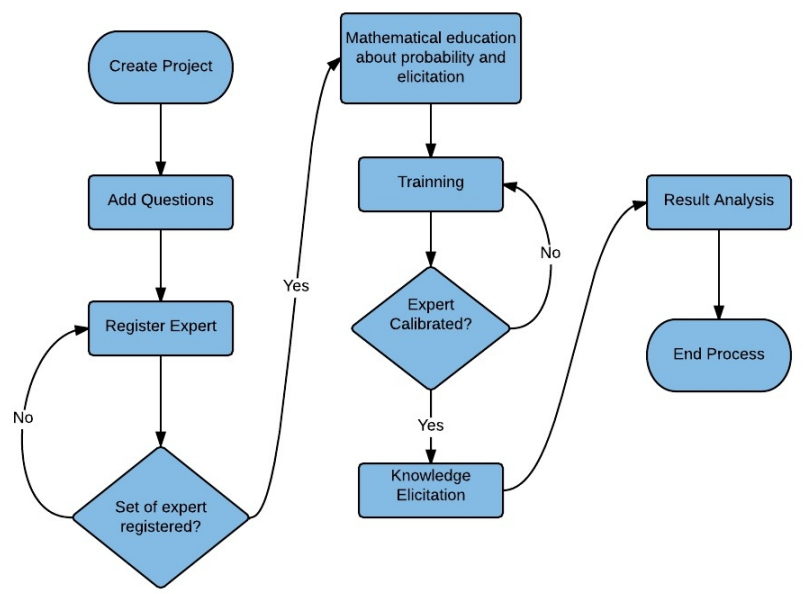

Figure 2. Fluxogram with the steps in the software Mesor Elicitor

In the elicitation step, dedicated to the cognitive forecasts, the expert should define the credible interval of the variable. In this specific example, the expert should estimate the minimum and maximum value that the series at a given moment. Using this estimation the expert is asked about his preference between the two intervals (minimum and mean: mean and maximum), and attribute a level of confidence to his choice between $50 \%$ e $100 \%$, considering that $50 \%$ means an aleatory choice and $100 \%$ means maximum reliability in the expert's answer. This process of choosing intervals is interactively repeated until the expert do not show more interest for any interval. More details are given in [3].

At every interaction, the Mesor Elicitor presents a graphic with the projection of the prediction from the expert for the time series, using the idea of graphics tools supported by authors as James et al. [34]. After each prediction, the software prints the point in the series and also include other values as maximum, minimum, mode, and mean for the expert can have a better idea about his prediction. This graphic has the purpose of facilitating the interaction of the expert with the tool.
Figure 3 illustrates an example of a time series containing the predictions from the expert presented graphically with Mesor Elicitor Software.

\subsection{Mathematical models for prediction}

To have the mathematical time series forecasts from the ARIMA models, first, one can consider to get the autocorrelation and partial autocorrelation functions from the time series. With these two functions, it is possible to discover the signature of the most appropriate ARIMA model [17]. The series 1269 will be used as an example to illustrate the procedure adopted to estimate the autocorrelation and partial autocorrelation function. All the demonstrated procedures were made in MatLab version 8.5.0. The Figure 4 shows the autocorrelation and partial autocorrelation function from the series.

Through a graphical analysis, the behavior of not soft decline in the autocorrelation function indicates that the time series has a stationary behavior. After analyzing the functions, it was estimated an ARIMA model $(1,0,0)$ or AR(1) because the gradual decline in the autocorrelation function and the cutoff in the lag 1 in the partial autocorrelation function, typical behavior of the $A R(1)$ model [17]. To confirm this model, it is used a pseudo-code presented in the MatLab documentation [35] that generates the values of BIC (Bayesian Information Criterion) [36] for some possible models in the time series. With this data it is possible to check which model better adjusts to the time series. In this way it is possible to evaluate that the approximation $p=1$ and $q=0$ is the most adequate to this time series. Defining the model it is possible use the pseudo-code and generate the predictions of the ARIMA models for the series. The Table 2 presents the approximation for the models using this procedure to the series on this paper.

\section{Results}

The experiment was based on comparing the cognitive model obtained through the elicitation of knowledge and the mathematical models obtained from the ARIMA estimation. In order to estimate the cognitive models, 33 individuals were interviewed. As this study is experimental, no individuals had previous knowledge about times series forecasting. Each interviewed was submitted to all the process of elicitation to get their estimates for the time series. The mathematical 


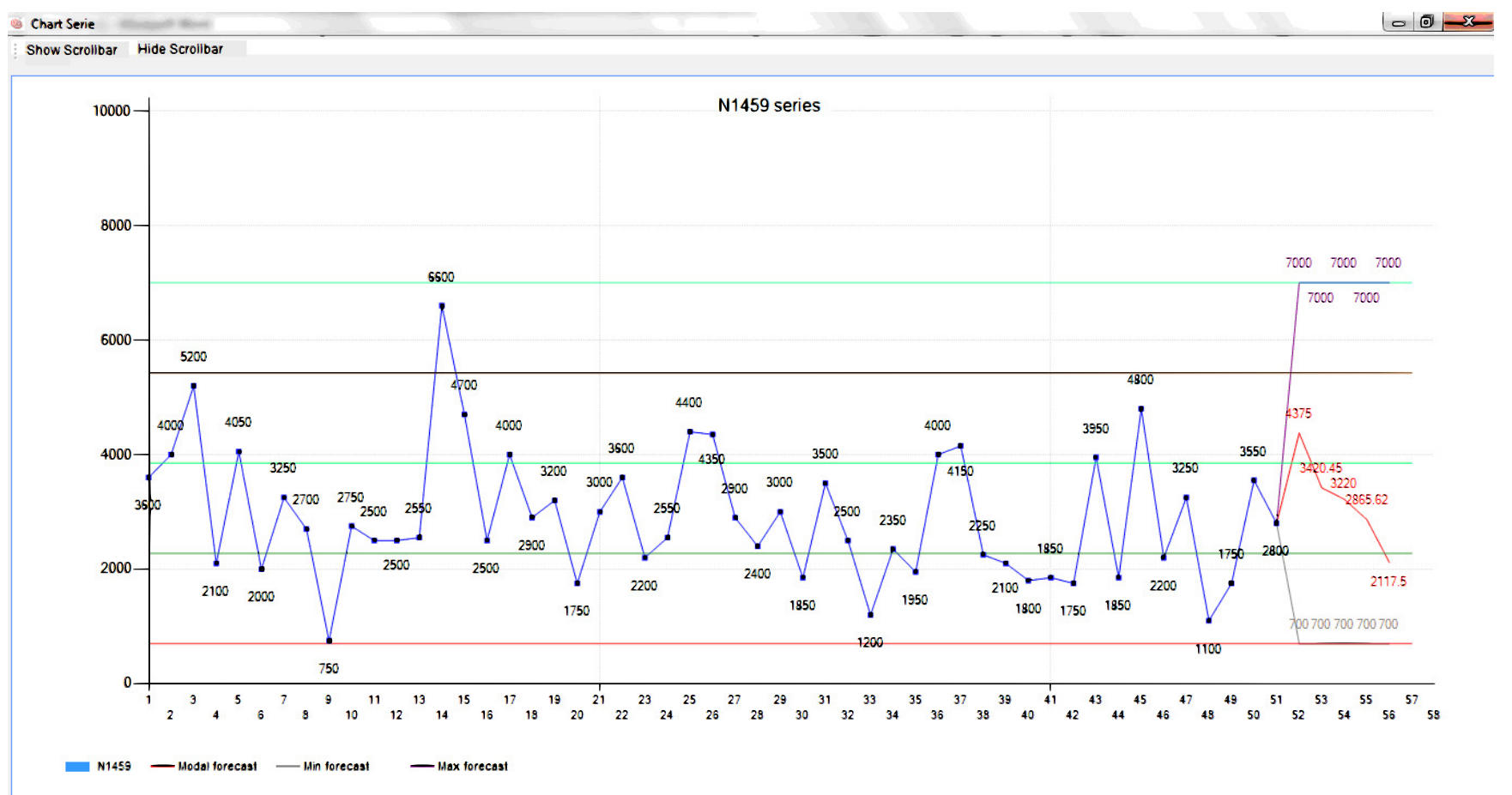

Figure 3. Graphical support to time series forecast in Mesor Elicitor

Table 2. ARIMA models selected to the series based on their autocorrelation, partial autocorrelation functions, and related Baysian Information Criterion (BIC) coefficients

\begin{tabular}{c|cccccccc}
\hline Serires & $\mathrm{N} 0236$ & $\mathrm{~N} 0290$ & $\mathrm{~N} 1037$ & $\mathrm{~N} 1268$ & $\mathrm{~N} 1269$ & $\mathrm{~N} 1459$ & $\mathrm{~N} 1708$ & $\mathrm{~N} 2355$ \\
\hline ARIMA & $(1,1,1)$ & $(0,2,0)$ & $(1,1,1)$ & $(0,1,0)$ & $(1,0,0)$ & $(2,0,2)$ & $(2,1,2)$ & $(2,1,1)$ \\
\hline
\end{tabular}

models were gotten in the MatLab.

\subsection{Comparison metrics}

There are some metrics to compare forecasting models. One of the most used metrics to check the accuracy of the forecast is the Mean Square Error (MSE) [37]. This measure is defined by:

$$
M S E=\frac{1}{N} \sum_{j=1}^{N}\left(d_{j}-p_{j}\right)^{2}
$$

in which $N$ represents the number of observations in the time series, $d_{j}$ is the $j^{\text {th }}$ target value of the series in the point $j$ and $p_{j}$ is the value of the prediction. The lesser the MSE the better the predictor.

Other measure is the Mean Absolute Percentage Error (MAPE). This measure is the percentage forecasting error, defined by:

$$
M A P E=\frac{100}{N} \sum_{j=1}^{N}\left|\frac{\left(d_{j}-p_{j}\right)}{d_{j}}\right|
$$

Like MSE measure, the smaller the value of MAPE the better the prediction is.
The metric Prediction of Change in Direction (POCID) is defined by;

$$
P O C I D=100 \frac{\sum_{j=1}^{N} D_{j}}{N},
$$

in which:

$$
D_{j}=\left\{\begin{array}{cc}
1 & \left(d_{j}-d_{j-1}\right)\left(p_{j}-p_{j-1}\right)>0 \\
0 & \text { otherwise }
\end{array}\right\}
$$

$D_{j}$ is the correct estimates about the direction of the series. This metric evaluate the percentage of right decisions about increasing the series value or decreasing in relation to the series previous point. The greater the POCID (limited to 100) the better the predictor is.

\subsection{Comparison models}

A summary of the performance results is presented in Table 3 . From the 24 comparisons between the evaluated metrics for both cognitive and mathematical forecasting models, 3 had equal results in POCID metric. Among the metrics which present different results, the cognitive models had a superior 

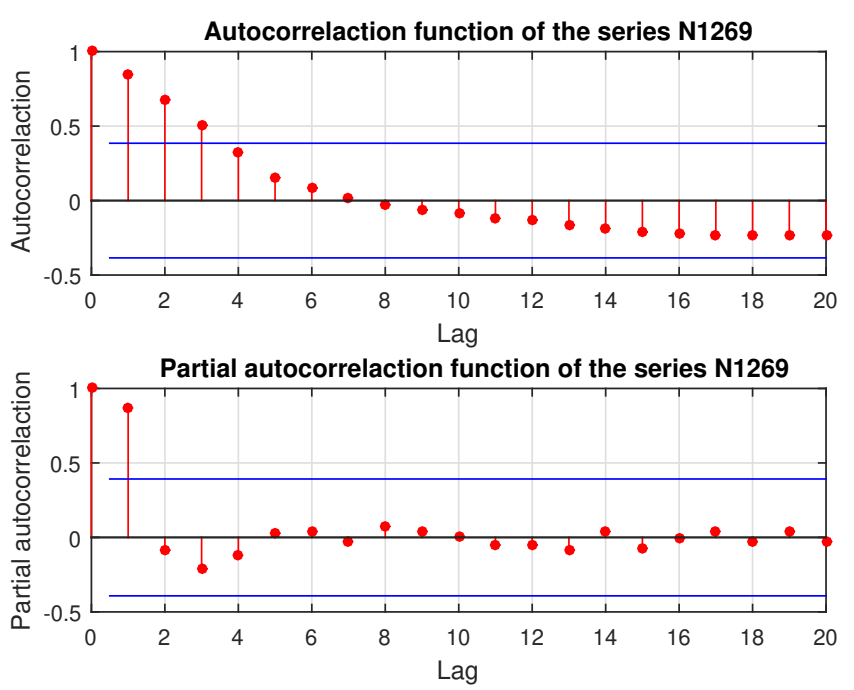

Figure 4. Autocorrelation and partial autocorrelation function from the series N1269

performance in 11 out of 21 comparisons. In general, the results of the cognitive models are aligned with the ones from authors like Lawrence [38]. They affirm that models based on expert opinions are able to be used in forecasting exercises. However, as observed in the metrics for the series N1269 and N1708, the cognitive models do not have a good result. These series present a decreasing behavior and the series N1708 also present too much oscillation. It suggests that cognitive models can have a bias when forecasting a decreasing series and the oscillation influences in the forecast. The small number of points, in some of the series, contributed to the performance of the cognitive model and made difficult the use of mathematical models, such as artificial neural networks. The results showed the potential of elicitation of knowledge applied by software in time series forecasting, that can make opinions of regular students who do not have the domain in time series forecasting in the same level of a forecast from ARIMA models.

\section{Conclusion}

It is undeniable the importance of expert's opinion in problems in which empirical data are scarce, absent, or only partially relevant. The human mind is a complex processor and with a mathematical and computational help can lead to attractive results. However, it is important to emphasize that many factors bring noise to cognitive models. This factors can have many sources as biases from the expert or even be present in the knowledge from the expert. Nevertheless, it is clear that expert's opinions are practical resources for the modeling of many problems including time series.

This paper used time series from real events in many areas. For this, the tendencies and seasonality of these series were more complex, making more difficult the prediction for both models. Also, the size of the series does not favor the use of more complex mathematical models. However, the comparison between the models was consistent and the results showed that the cognitive models had at least equivalent accuracy in comparison to the ARIMA models, even interviewing experts who did not have previous knowledge regarding time series forecasting. Those results highlight that expert's opinions can be used as forecasters for time series and highlight perspectives as the comparison of forecasts from mathematical models and cognitive models in other problems.

\section{Acknowledgements}

The authors would like to thank the Science and Technology Support Foundation of Pernambuco (FACEPE) Brazil, Brazilian National Council for Scientific and Technological Development (CNPq) and Coordenação de Aperfeiçoamento de Pessoal de Nível Superior - Brasil (CAPES) - Finance Code 001 by financial support for the development of this research.

\section{Author contributions}

- Ademir Batista dos Santos Neto: This author is the main author of the paper. He was responsible for study the theory, develop the results and written the article. Also he is one of the authors of the software MESOR ELICITATION.

- Maria da Conceição Moraes Batista: This author was responsible for the data analysis in the paper.

- Paulo Renato Alves Firmino: This author was the responsible for the prediction using the cognitive models. The author developed the theory and also contributed in develop the MESOR ELICITATION software.

- Tiago Alessandro Espíndola Ferreira: This author was the responsible for the mathematical models prediction using ARIMA and for comparing the results from the two models.

\section{References}

[1] WICKENS, C. D. et al. Engineering psychology \& human performance. [S.1.]: Psychology Press, 2015.

[2] HAN, J. A goms-based granular computing model for human-computer interaction design. In: IEEE. Service Operations, Logistics, and Informatics (SOLI), 2011 IEEE International Conference on. [S.1.], 2011. p. 243-248.

[3] FIRMINO, P. R. A.; DROGUETT, E. L. An expert opinion elicitation method based on binary search and bayesian intervals. International Journal of Risk Assessment and Management, Inderscience Publishers (IEL), v. 18, n. 3-4, p. 336$362,2015$. 
Table 3. Comparison between Cognitive (Cognit) and mathematical (Math) models by the presented metrics

\begin{tabular}{lllll}
\hline Series & Model & MSE & MAPE & POCID \\
\hline \multirow{2}{*}{ N0236 } & Cognit & 16548 & $1.85 \%$ & $66 \%$ \\
& Math & 25813 & $2.49 \%$ & $33 \%$ \\
\hline \multirow{2}{*}{ N0290 } & Cognit & 10147 & $1.38 \%$ & $50 \%$ \\
& Math & 295191 & $8.59 \%$ & $75 \%$ \\
\hline \multirow{2}{*}{ N1037 } & Cognit & 43881 & $3.9 \%$ & $16 \%$ \\
& Math & 102117 & $5.8 \%$ & $48 \%$ \\
\hline \multirow{2}{*}{ N1268 } & Cognit & 89132 & $4.26 \%$ & $50 \%$ \\
& Math & 2572 & $0.65 \%$ & $50 \%$ \\
\hline \multirow{2}{*}{ N1269 } & Cognit & 12870 & $1.9 \%$ & $0 \%$ \\
& Math & 581 & $0.38 \%$ & $80 \%$ \\
\hline \multirow{2}{*}{ N1459 } & Cognit & 1676111 & $59.76 \%$ & $24 \%$ \\
& Math & 981045 & $47.41 \%$ & $12 \%$ \\
\hline \multirow{2}{*}{ N1708 } & Cognit & 1584691 & $63 \%$ & $20 \%$ \\
& Math & 2620559 & $47 \%$ & $20 \%$ \\
\hline \multirow{2}{*}{ N0236 } & Cognit & 13212 & $2.24 \%$ & $50 \%$ \\
& Math & 132480 & $8.82 \%$ & $50 \%$ \\
\hline
\end{tabular}

[4] SANTOS, W. Barbosa dos. Probablisitic analysis of risk by Baysians networks: An application to construct multilateral wells. Tese (MSc dissertation) - Federal University of Pernambuco, 2005.

[5] MCCORMACK, K. P.; BRONZO, M.; OLIVEIRA, M. P. V. A probabilistic approach to risk analysis in supply chain (in portugues). Revista Produção Online, v. 10, n. 3, p. 577$598,2010$.

[6] FERREIRA, R. J. et al. Strategical map for human resources programs: Evaluating the efficience of baysian networks. Management and Production, SciELO Brasil, v. 17, n. 1, 2010.

[7] O'HAGAN, A. et al. Uncertain judgements: eliciting experts' probabilities. [S.1.]: John Wiley \& Sons, 2006.

[8] AYYUB, B. M. Elicitation of expert opinions for uncertainty and risks. [S.1.]: CRC press, 2001.

[9] COOKE, R. Experts in uncertainty: opinion and subjective probability in science. [S.1.]: Oxford University Press on Demand, 1991.

[10] LEU, G.; ABBASS, H. A multi-disciplinary review of knowledge acquisition methods: From human to autonomous eliciting agents. Knowledge-Based Systems, v. 105, p. 1 - 22, 2016. Disponível em: 〈http://www.sciencedirect.com/science/ article/pii/S0950705116000988 $\rangle$.

[11] SONG, B.; JIANG, Z.; LI, X. Modeling knowledge need awareness using the problematic situations elicited from questions and answers. Knowledge-Based Systems, v. 75, p. 173 - 183, 2015. Disponível em: 〈http://www.sciencedirect.com/ science/article/pii/S0950705114004341〉.

[12] CLEMEN, R. T.; REILLY, T. Making hard decisions with DecisionTools. [S.1.]: Cengage Learning, 2013.

[13] HODGE, R. et al. Eliciting engineering knowledge about reliability during design-lessons learnt from implementation.
Quality and Reliability Engineering International, Wiley Online Library, v. 17, n. 3, p. 169-179, 2001.

[14] GARTHWAITE, P. H.; KADANE, J. B.; O'HAGAN, A. Statistical methods for eliciting probability distributions. Journal of the American Statistical Association, Taylor \& Francis, v. 100, n. 470, p. 680-701, 2005.

[15] SHADBOLT, N. R.; SMART, P. R. Knowledge elicitation. Evaluation of Human Work (4th ed.). CRC Press, Boca Raton, Florida, USA, p. 163-200, 2015.

[16] KIRCHGÄSSNER, G.; WOLTERS, J.; HASSLER, U. Introduction to modern time series analysis. [S.1.]: Springer Science \& Business Media, 2012.

[17] BOX, G. E. et al. Time series analysis: forecasting and control. [S.1.]: John Wiley \& Sons, 2015.

[18] HURVICH, C. M.; TSAI, C.-L. Regression and time series model selection in small samples. Biometrika, Oxford University Press, v. 76, n. 2, p. 297-307, 1989.

[19] AZOFF, E. M. Neural network time series forecasting of financial markets. [S.1.]: John Wiley \& Sons, Inc., 1994.

[20] KIM, K.-j. Financial time series forecasting using support vector machines. Neurocomputing, Elsevier, v. 55, n. 1-2, p. 307-319, 2003.

[21] FERREIRA， T. A.; VASCONCELOS， G. C.; ADEODATO, P. J. A new intelligent system methodology for time series forecasting with artificial neural networks. Neural Processing Letters, Springer, v. 28, n. 2, p. 113-129, 2008.

[22] NETO, P. S. de M. et al. A perturbative approach for enhancing the performance of time series forecasting. Neural Networks, v. 88, p. 114 - 124, 2017. Disponível em: 〈http://www.sciencedirect.com/science/ article/pii/S0893608017300308 $\rangle$. 
[23] KUREMOTO, T. et al. Time series forecasting using a deep belief network with restricted boltzmann machines. Neurocomputing, Elsevier, v. 137, p. 47-56, 2014.

[24] FIRMINO, P. R. et al. Eliciting engineering judgments in human reliability assessment. In: IEEE. Reliability and Maintainability Symposium, 2006. RAMS'06. Annual. [S.1.], 2006. p. 512-519.

[25] FORD, K. M.; ADAMS-WEBBER, J. R. Knowledge acquisition and constructivist epistemology. The psychology of expertise: Cognitive research and empirical AI, SpringerVerlag, p. 121-136, 1992.

[26] COOKE, N. J. Varieties of knowledge elicitation techniques. International Journal of Human-Computer Studies, Elsevier, v. 41, n. 6, p. 801-849, 1994.

[27] KEREN, G. Calibration and probability judgements: Conceptual and methodological issues. Acta Psychologica, Elsevier, v. 77, n. 3, p. 217-273, 1991.

[28] BRIER, G. W. Verification of forecasts expressed in terms of probability. Monthly weather review, v. 78, n. 1, p. 1-3, 1950.

[29] EHLERS, R. S. Times series analysis. Stathistical and Geo Infromation Laboratory. Federal University of Parana, 2007.

[30] HYNDMAN, R. J.; ATHANASOPOULOS, G. Forecasting: principles and practice. [S.1.]: OTexts, 2014.
[31] MAKRIDAKIS, S.; HIBON, M. The m3-competition: results, conclusions and implications. International journal of forecasting, Elsevier, v. 16, n. 4, p. 451-476, 2000.

[32] O'HAGAN, A. Probabilistic uncertainty specification: Overview, elaboration techniques and their application to a mechanistic model of carbon flux. Environmental Modelling \& Software, Elsevier, v. 36, p. 35-48, 2012.

[33] KYNN, M. Designing elicitor: Software to graphically elicit expert priors for logistic regression models in ecology. Available from www.winbugs-development. org. uk, Citeseer, 2006.

[34] JAMES, A.; CHOY, S. L.; MENGERSEN, K. Elicitator: an expert elicitation tool for regression in ecology. Environmental Modelling \& Software, Elsevier, v. 25, n. 1, p. 129-145, 2010.

[35] MATLAB, M. The language of technical computing. The MathWorks, Inc. http://www.mathworks. com, 2012.

[36] SCHWARZ, G. et al. Estimating the dimension of a model. The annals of statistics, Institute of Mathematical Statistics, v. 6, n. 2, p. 461-464, 1978.

[37] SILVA, D. A. et al. Measurement of fitness function efficiency using data envelopment analysis. Expert Systems with Applications, Elsevier, v. 41, n. 16, p. 7147-7160, 2014.

[38] LAWRENCE, M. et al. Judgmental forecasting: A review of progress over the last 25years. International Journal of Forecasting, Elsevier, v. 22, n. 3, p. 493-518, 2006. 